\title{
Surgical treatment of type A Acute Aortic Dissection based on Geneva algorithm
}

\author{
Burak Can Depboylu', Leon Finci', Patrick O Myers ${ }^{1}$, Saziye Karaca', Dominique Vala', Jalal Jolou', \\ Parmeseeven Mootoosamy ${ }^{1 *}$, Marck Licker ${ }^{2}$, Karim Bendjelid ${ }^{3}$, Afksendiyos Kalangos $^{1}$, Mustafa Cikirikcioglu ${ }^{1}$ \\ From World Society of Cardiothoracic Surgeons 25th Anniversary Congress, Edinburgh \\ Edinburgh, UK. 19-22 September 2015
}

\section{Background/Introduction}

Type A Acute Aortic Dissection (AAAD) is a highly deadly disease. Management of AAAD suspicion is extremely important in order to gain time and increase the likelihood of survival.

\section{Aims/Objectives}

The aim of this study is to review our experience based on our local algorithm developed for the assessment and management of patients with AAAD suspicion over the last 8 years.

\section{Methods}

All patients who underwent an emergency surgery for AAAD between 2007 and 2014 following our algorithm were assessed (Table). Their clinical situation at admission, evaluation, operative and postoperative data were evaluated retrospectively. Continuous variables were expressed as mean \pm standard deviation; categorical variables were shown as frequency and percentage.

\section{Results}

A total of 68 patients were included during the study period. The mean age was $61 \pm 13$ years, with 42 men $(65 \%)$. Supracoronary ascending aorta replacement was the primary surgical procedure (in 31 patients, $46 \%$ ). The mean cardiopulmonary bypass, cross clamp and circulatory arrest times were $3.2 \pm 1.6,2.1 \pm 1.2$ and $0.4 \pm 0.2$ hours. Acute renal failure $(27,40 \%)$, re-operation $(18,26 \%)$ and pneumonia $(14,20 \%)$ were the main postoperative complications. Mean intensive care unit stay and hospitalization times were $5.8 \pm 6.2$ and $26.5 \pm 53.5$ days. There

${ }^{1}$ Division of Cardiovascular Surgery, Hospitals and Medical Faculty of Geneva, Geneva, Geneva, 1211, Switzerland

Full list of author information is available at the end of the article were 14 perioperative deaths (21\%) and 18 hospital deaths (26\%). The 6-year survival was $67.5 \%$.

\section{Conclusion}

Our institutional experience in managing AAAD is comparable to results from other centers. Standardizing management using an algorithm is important to gain time for rapid decision-making and having successful outcomes in centers with limited volume.

\section{Authors' details}

'Division of Cardiovascular Surgery, Hospitals and Medical Faculty of Geneva, Geneva, Geneva, 1211, Switzerland. 'Division of Anaesthesiology University, Hospitals and Medical Faculty of Geneva, Geneva, Geneva, 1211, Switzerland. ${ }^{3}$ Division of Intensive Care, Hospitals and Medical Faculty of Geneva, Geneva, Geneva, 1211, Switzerland.

Published: 16 December 2015

doi:10.1186/1749-8090-10-S1-A313

Cite this article as: Depboylu et al:: Surgical treatment of type A Acute Aortic Dissection based on Geneva algorithm. Journal of Cardiothoracic Surgery 2015 10(Suppl 1):A313.

Submit your next manuscript to BioMed Central and take full advantage of:

- Convenient online submission

- Thorough peer review

- No space constraints or color figure charges

- Immediate publication on acceptance

- Inclusion in PubMed, CAS, Scopus and Google Scholar

- Research which is freely available for redistribution

Submit your manuscript at www.biomedcentral.com/submit
() Biomed Central 


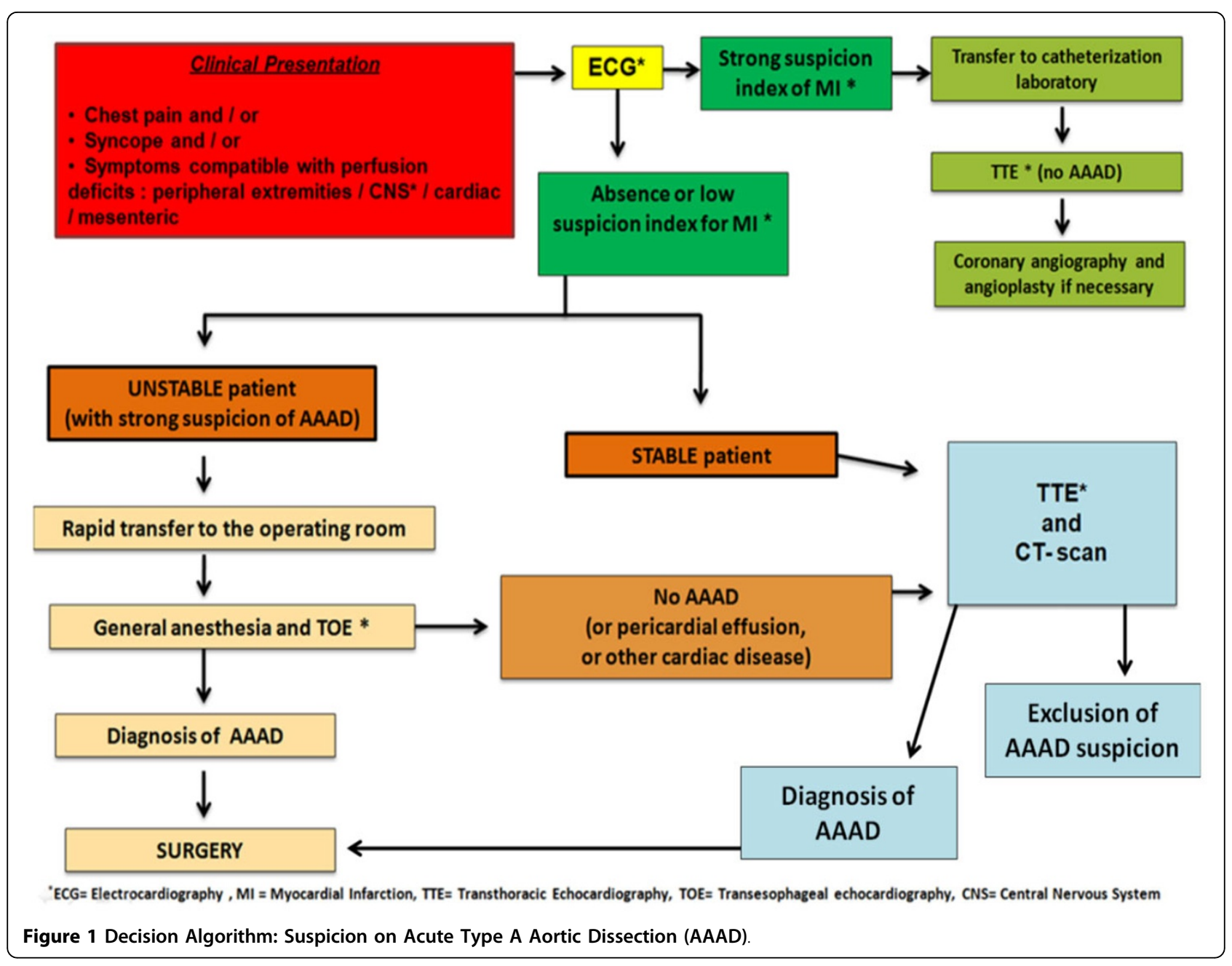

